\title{
Fabrication and Crystallization of ZnO-SLS Glass Derived Willemite Glass-Ceramics as a Potential Material for Optics Applications
}

\author{
Mohd Hafiz Mohd Zaid, ${ }^{1}$ Khamirul Amin Matori, ${ }^{1,2}$ \\ Sidek Hj. Abdul Aziz, ${ }^{1}$ Halimah Mohamed Kamari, ${ }^{1}$ Wan Mahmood Mat Yunus, ${ }^{1}$ \\ Zaidan Abdul Wahab, ${ }^{1}$ and Nur Farhana Samsudin ${ }^{2}$ \\ ${ }^{1}$ Department of Physics, Faculty of Science, Universiti Putra Malaysia (UPM), 43400 Serdang, Selangor, Malaysia \\ ${ }^{2}$ Materials Synthesis and Characterization Laboratory, Institute of Advanced Technology, Universiti Putra Malaysia (UPM), \\ 43400 Serdang, Selangor, Malaysia \\ Correspondence should be addressed to Khamirul Amin Matori; khamirul@upm.edu.my
}

Received 29 October 2015; Revised 3 January 2016; Accepted 6 January 2016

Academic Editor: Austin Nevin

Copyright (C) 2016 Mohd Hafiz Mohd Zaid et al. This is an open access article distributed under the Creative Commons Attribution License, which permits unrestricted use, distribution, and reproduction in any medium, provided the original work is properly cited.

Willemite glass-ceramics were successfully derived from conventional melt-quench ZnO-SLS precursor glass by an isothermal heat treatment process. The effect of heat treatment temperatures on the physical properties was investigated by Archimedes principle and linear shrinkage. The generation of willemite crystal phase and morphology with increase in heat treatment temperature was examined by X-ray diffraction (XRD), Fourier transform infrared (FTIR), and field emission scanning electron microscopy (FESEM) techniques. X-ray diffraction revealed that the metastable $\beta-\mathrm{Zn}_{2} \mathrm{SiO}_{4}$ and thermodynamically stable zinc orthosilicate $\alpha$ $\mathrm{Zn}_{2} \mathrm{SiO}_{4}$ phases can be observed at temperatures above $700^{\circ} \mathrm{C}$. The experimental results indicated that the density and shrinkage of the glass-ceramic vary with increasing the sintering temperature. FTIR studies showed that the structure of glass-ceramic consists of $\mathrm{SiO}_{2}$ and $\mathrm{ZnO}_{4}$ units and exhibits the structural evolution of willemite glass-ceramics. The characteristic of strong vibrational bands can be related to the $\left[\mathrm{SiO}_{4}\right]^{4-}$ tetrahedron corresponding to reference spectra of willemite.

\section{Introduction}

Recently, manufacturing industries played an important role in economic growth. However, this rapid industrialization generates enormous amount of waste such as glass waste which necessitates different attitudes toward solid waste management [1]. Therefore, converting these solid wastes into more valuable and environment friendly products is a new focus across the world. This is in line with the increasing demand for limited natural resources; hence waste recovery provides alternative resources which reduces dependency on natural resource such as sand-silica for production of glasses [2] and glass-ceramics [3, 4]. Among silica-rich wastes, soda lime silica (SLS) glass from bottle banks has attracted much attention. SLS glass from urban waste consists mainly of silicon $\left(\mathrm{SiO}_{2}\right)$, sodium $\left(\mathrm{Na}_{2} \mathrm{O}\right)$, and calcium oxides $(\mathrm{CaO})$. Thanks to its potential of low temperature viscous flow sintering, SLS glass can be considered as a good candidate for total, or partial, replacement of the natural fluxes [5-7]. Glassceramics possess many favorable properties including low density, low thermal conductivity, high surface area, virtuous thermal shock resistance, and great specific strength [8].

Glass-ceramic containing willemite $\left(\mathrm{Zn}_{2} \mathrm{SiO}_{4}\right)$ has been known, for many years, as materials for electronic applications and has been identified as a suitable host matrix for many rare earth and transition metal dopant ions for efficient luminescence [9-14]. Willemite is one of the zinc ore minerals having the phenakite structure. In $\mathrm{Zn}_{2} \mathrm{SiO}_{4}$, all the atoms occupy general position and are composed of tetrahedral framework where zinc and silicon are positioned in three different fourfold crystallographic sites: two slightly different zinc sites $\mathrm{Zn}_{1}\left(\langle\mathrm{Zn}-\mathrm{O}\rangle \mathbf{1 . 9 5 0 \AA )}\right.$ and $\mathrm{Zn}_{2}(\langle\mathrm{Zn}-\mathrm{O}\rangle \mathbf{1 . 9 6 1} \AA)$, and $\mathrm{Si}(\langle\mathrm{Si}-\mathrm{O}\rangle 1.635 \AA)$, thus resulting in rhombohedra symmetry with lattice parameters $a=b \sim 13.948 \AA$ and 
$c \sim 9.315 \AA[15]$. This kind of rigid lattice, with only noncentrosymmetric cationic sites, gives the chance to get special optical properties.

Willemite or zinc silicate $\left(\mathrm{Zn}_{2} \mathrm{SiO}_{4}\right)$ is known as an ideal host material for phosphor and optoelectronic material due to its large band gap of $5.5 \mathrm{eV}$, chemical stability, and transparency in the UV-visible range [16]. Willemite also has attractive features such as much larger exciting binding energies which make it suitable for applications in coating, cathode ray tubes (CRT), plasma display panels (PDPs), laser crystals, upconversion luminescent materials, electroluminescent devices, and catalyst [17-22]. Most of research has only been focused on a thermal dynamically stable zinc orthosilicate $\left(\alpha-\mathrm{Zn}_{2} \mathrm{SiO}_{4}\right)$ with the different micro- or nanostructures produced by solid-state reaction, radio frequency magnetron sputtering, spray pyrolysis, solgel, polymer precursor, and hydrothermal methods [2328]. Producing of willemite phosphor without incorporating expensive material and high temperature mechanism is of interest of researchers so that low energy processes might be developed. However, many valuable results have been kept within industry because willemite is a highly important technological material.

In the present work, the preparation of novel ZnO-SLS glass by conventional melt-quench technique and willemite glass-ceramics by isothermal controlled crystallization of precursor glasses is reported. The main advantage of $\mathrm{ZnO}$ SLS based glass systems compared to normal zinc-sodalime-silica glass systems is that the melting and processing temperature will decrease substantially. This will reduce the cost of production of this glass-ceramic. In this context, the major purposes of this work are to fabricate and characterize willemite glass-ceramics from waste materials as a potential material for use in optics application.

\section{Experimental Procedure}

High purity zinc oxide ( $\mathrm{ZnO})$ (99.99\%, Aldrich) powders and soda lime silica (SLS) waste glass powders are used as a raw material. Homogeneous mixtures of batches $(\sim 100 \mathrm{~g})$ with empirical formula of $(\mathrm{ZnO})_{0.5}(\mathrm{SLS})_{0.5}$ are obtained by milling process and further melting at $1400^{\circ} \mathrm{C}$ for $2 \mathrm{~h}$. The glass frits are obtained by quenching of the melt in the cold water. Then, the frits are dried and then milled in a highspeed porcelain mill, resulting in powders with the mean particle size of $45 \mu \mathrm{m}$. Next, the mixtures are uniaxial pressed with an applied load of 3.5 tons for 15 min using polyvinyl alcohol (PVA) as the binder to obtain the pellet samples. The dimension of pellets was $10 \mathrm{~mm}$ in diameter and $2 \mathrm{~mm}$ thick. The pellets were subjected to heat treatment process in the range of $600-1000^{\circ} \mathrm{C}$ for $2 \mathrm{~h}$ in air at a slow heating rate of $10^{\circ} \mathrm{C} / \mathrm{min}$.

Differential thermal calorimetry of precursor glass powder was carried out on glass powders with particle size ranging from 45 to $100 \mu \mathrm{m}$, using a Diamond Pyris TG/DTA (Perkin Elmer) with $\mathrm{Al}_{2} \mathrm{O}_{3}$ powder as reference material in a dynamic pure nitrogen atmosphere at a flow rate of $50 \mathrm{~cm}^{3} / \mathrm{min}$ at the temperature range between 400 and $900^{\circ} \mathrm{C}$
TABLE 1: Chemical composition of SLS glass waste and ZnO-SLS glass (wt.\%).

\begin{tabular}{lcc}
\hline Oxide & SLS glass container & ZnO-SLS glass \\
\hline $\mathrm{SiO}_{2}$ & 69.5 & 34.9 \\
$\mathrm{CaO}$ & 11.3 & 5.7 \\
$\mathrm{Na}_{2} \mathrm{O}$ & 12.5 & 6.3 \\
$\mathrm{Al}_{2} \mathrm{O}_{3}$ & 2.8 & 1.3 \\
$\mathrm{MgO}$ & 2.0 & 1.0 \\
$\mathrm{ZnO}$ & 0 & 49.8 \\
Others & 1.9 & 1.0 \\
\hline
\end{tabular}

at $10^{\circ} \mathrm{C} / \mathrm{min}$ to ascertain the glassy nature of the precursor glass and to find out $T_{g}$ and crystallization peak temperature $\left(T_{c}\right)$. The percentage of linear shrinkage (LS) is determined by calculating the difference between the initial dimensions $\left(D_{i}\right)$ and the final dimensions $\left(D_{f}\right)$ of the sintered pellet. Then, the values are divided by initial dimension $\left(D_{i}\right)$ and multiplied with $100 \%$ (1). The linear shrinkage of the sample is then calculated using the following equation:

$$
\mathrm{LS}=\left[\frac{\left(D_{i}-D_{f}\right)}{D_{i}}\right] \times 100 \% .
$$

The densities $(\rho)$ of the samples are measured in room temperature by the standard Archimedes method and using acetone as the immersion fluid. Firstly, the samples are weighed in air, $W_{\text {air }}$, and then measured in an immersion liquid (acetone) $W_{\mathrm{ac}}$, with density $\rho_{\mathrm{ac}}=0.789 \mathrm{~g} \mathrm{~cm}^{-3}$. The densities of the samples are then calculated using the following equation:

$$
\rho=\frac{W_{\mathrm{air}} \rho_{\mathrm{ac}}}{\left(W_{\mathrm{air}}-W_{\mathrm{ac}}\right)},
$$

where the estimated error is $\pm 0.001 \mathrm{~g} \mathrm{~cm}^{-3}$.

The evolution of crystalline phases of the sintered sample at different temperatures was determined by $\mathrm{X}$-ray diffraction analysis (Philips $\mathrm{X}$-ray diffractometer with $\mathrm{Cu}-\mathrm{K} \alpha$ radiation) and Fourier-transform infrared spectra (FTIR) recorded with a Perkin Elmer Spectrum 100 series. Field emission scanning electron microscopy (FE-SEM, FEI NOVA NanoSEM 230) was used for microstructure observation.

\section{Results and Discussion}

Energy dispersive X-ray fluorescence (EDXRF) is a nondestructive analytical technique used to characterize the chemical composition of SLS glass waste and ZnO-SLS glass samples. Chemical compositions present in the glass samples were analyzed by EDXRF as shown in Table 1. From the table, the multicompounds like $\mathrm{SiO}_{2}, \mathrm{CaO}, \mathrm{Na}_{2} \mathrm{O}, \mathrm{Al}_{2} \mathrm{O}_{3}, \mathrm{MgO}$, $\mathrm{ZnO}$, and other minor elements were detected in the samples. The increase of $\mathrm{ZnO}$ content to the SLS glass has resulted in a percentage reduction of other elements in the glass samples.

Differential thermal analysis (DTA) was recorded for the precursor glass powder to determine $T_{g}$ and crystallization 
TABLE 2: The density and linear shrinkage of the glass-ceramic sample at various heat treatment temperatures.

\begin{tabular}{lcc}
\hline Temperature $\left({ }^{\circ} \mathrm{C}\right)$ & Density $\left(\mathrm{g} / \mathrm{cm}^{3}\right)$ & Linear shrinkage $(\%)$ \\
\hline 27 & 2.84 & 0 \\
600 & 2.95 & 0.1 \\
700 & 3.28 & 0.5 \\
800 & 3.58 & 1.1 \\
900 & 3.89 & 2.6 \\
1000 & 3.96 & 3.7 \\
\hline
\end{tabular}

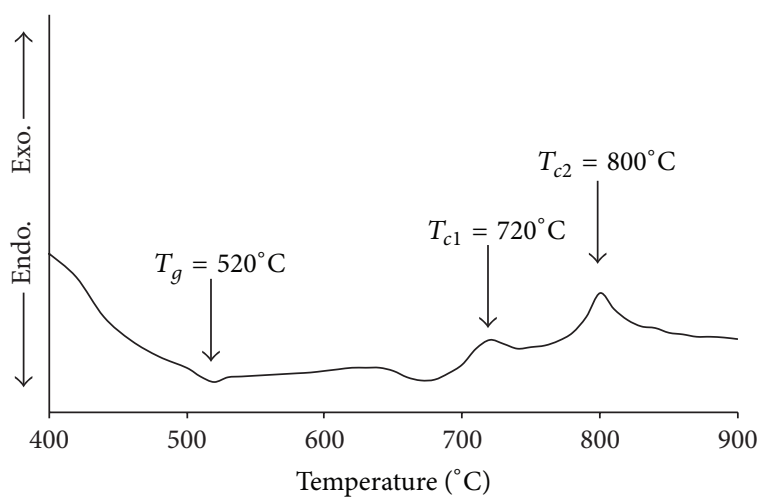

FIgURE 1: DTA curves of ZnO-SLS glasses.

temperatures. The DTA of the precursor glass is shown in Figure 1. $T_{g}$ estimated from this curve is found to be $520^{\circ} \mathrm{C}$. Besides, from the figure, two exothermic peaks at $710^{\circ} \mathrm{C}$ $\left(T_{c 1}\right)$ and $800^{\circ} \mathrm{C}\left(T_{c 2}\right)$ have been detected. The onset of first crystallization peak $\left(T_{c 1}\right)$ is at $710^{\circ} \mathrm{C}$ and this peak $\left(T_{c 1}\right)$ is corresponding to the $\beta$-willemite $\left(\beta-\mathrm{Zn}_{2} \mathrm{SiO}_{4}\right)$ crystallization. The crystallization peak which is peaking at $800^{\circ} \mathrm{C}\left(T_{c 2}\right)$ is due to the formation of $\alpha$-willemite $\left(\alpha-\mathrm{Zn}_{2} \mathrm{SiO}_{4}\right)$. This fact is confirmed by XRD and is presented in the XRD section.

Table 2 shows the variations of density and linear shrinkage of glass at various heat treatment temperatures. It can be seen that the density of the sample increases with increasing the heat treatment temperature from 2.84 to $3.96 \mathrm{~g} / \mathrm{cm}^{3}$. It is mainly due to the structure compactness of the glass-ceramic sample with the increasing of heat treatment temperature. Generally, the increasing in pressure (temperature) on a material will decrease the volume of the material and thus increases its density [29]. Further, as heat treatment temperature increases, grains shift to obtain more dense packing. As it is expected, at $600^{\circ} \mathrm{C}$ the shrinkage is too small and arguably there is no change. As heat treatment temperature increases up to $1000^{\circ} \mathrm{C}$, a slight increase in the shrinkage of the sample is observed which can be attributed to the effect of alloying element factors such as the diffusion coefficients, thermal expansion coefficients, and the volume change during the phase transformations upon cooling. Besides, increases in the density of the sample have also resulted in the changes of the cross-link density due to the formation of willemite crystal. It can be observed that the density of the sample increases when sintered; this may be attributed to the decrease in the bond length due to the formation of $\mathrm{ZnO}_{4}$ octahedral groups

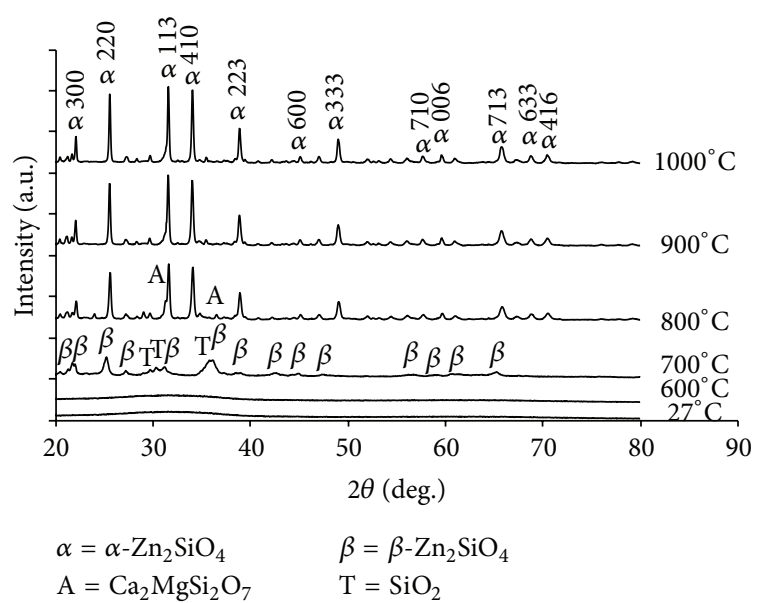

FIGURE 2: X-ray diffraction of the sample at various heat treatment temperatures.

[30]. Solid oxides reveal mixed ionic and covalent bonding. The ionic bond fraction decreases as the cation size and coordination number decrease while the oxidation state of the ion increases. This results in a decrease in bond length between $\mathrm{Zn}^{2+}$ and $\mathrm{O}^{2-}$ ion and formation of a close-packed structure, consequently increasing the density of the glassceramics.

The XRD pattern of the glass and glass-ceramics is shown in Figure 2. No diffraction peak appears for the precursor glass sample heat treated below $600^{\circ} \mathrm{C}$, which indicates that these samples are amorphous in nature. Crystallization starts at temperatures higher than $600^{\circ} \mathrm{C}$. The diffraction peak of the samples treated for different temperature above $700^{\circ} \mathrm{C}$ for $2 \mathrm{~h}$ is indexed and it resembled to some extent willemite $\left(\alpha-\mathrm{Zn}_{2} \mathrm{SiO}_{4}\right)$ phase (JCPDS file 37-1485). By increasing the heat treatment temperature to $700^{\circ} \mathrm{C}$, the $\beta$-willemite $(\beta$ $\left.\mathrm{Zn}_{2} \mathrm{SiO}_{4}\right)$ and minor tridymite $\left(\mathrm{SiO}_{2}\right)$ phases with JCPDS number of 14-0653 and 75-0638 are formed. Regarding thermodynamically metastable phases, two crystallographic variations are known and each is referred to as $\beta$-phase $\mathrm{Zn}_{2} \mathrm{SiO}_{4}$. The crystal system is considered to be orthorhombic. The $\beta$ phase $\mathrm{Zn}_{2} \mathrm{SiO}_{4}$ was probably the same as that produced by melting and annealing $\mathrm{ZnO}$ and $\mathrm{SiO}_{2}$ in which the $\mathrm{Si} / \mathrm{Zn}$ molar ratio was 1.7 more than the stoichiometric value of 0.5 [31]. By further increasing the heat treatment temperature to $800^{\circ} \mathrm{C}$, the $\beta-\mathrm{Zn}_{2} \mathrm{SiO}_{4}$ transforms to $\alpha$-willemite $\left(\alpha-\mathrm{Zn}_{2} \mathrm{SiO}_{4}\right)$ and minor akermanite $\left(\mathrm{Ca}_{2} \mathrm{MgSi}_{2} \mathrm{O}_{7}\right)$ phase with JCPDS number of 37-1485 and 76-0841. Akermanite forms solid solutions, being the end member of melilite, which belongs to the group of sorosilicates [32]. Akermanite usually occurs in igneous and metamorphic rocks and meteorites, but also in the slag of blast furnaces which can be considered as an evidence of their high chemical stability at elevated temperatures. According to Figure 2, akermanite is the minor crystalline phase after glass sample was treated at $700^{\circ} \mathrm{C}$. The intensity of akermanite $\mathrm{X}$-ray peaks decreased when the temperature of the heat treatment increased. These results indicate that the amount of $\mathrm{CaO}$ and $\mathrm{MgO}$ may play a key role in the yield of akermanite phase in the investigated system. 


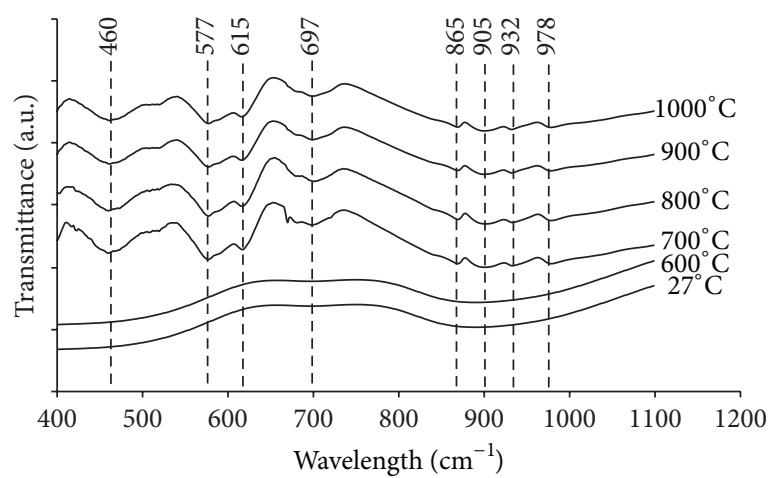

FIGURE 3: Fourier transforms infrared spectra of the sample at various heat treatment temperatures.

Hence, a deep understanding of the role of $\mathrm{CaO}$ and $\mathrm{MgO}$ has to be resolved in future studies. Increasing the temperature to $1000^{\circ} \mathrm{C}$ for 2 hours resulted in better crystallinity in the glassceramic sample.

The $\alpha$-phase is a nesosilicate or orthosilicate that consists of isolated $\mathrm{SiO}_{4}{ }^{4-}$ tetrahedrons and $\mathrm{ZnO}_{4}{ }^{6-}$ tetrahedrons [11]. The twelve major diffraction peaks at $2 \theta=22.07^{\circ}, 25.54^{\circ}$, $31.53^{\circ}, 34.00^{\circ}, 38.82^{\circ}, 48.93^{\circ}, 45.01^{\circ}, 46.97^{\circ}, 48.93^{\circ}, 57.60^{\circ}$, $59.52^{\circ}, 65.63^{\circ}, 68.67^{\circ}$, and $70.37^{\circ}$ corresponding planes are (300), (220), (113), (410), (223), (600), (333), (710), (006), (713), (633), and (416) and can be indexed using standard diffraction pattern of $\alpha-\mathrm{Zn}_{2} \mathrm{SiO}_{4}$ crystal phase (Figure 2). It is found that advancement of heat treatment process leads to an increase in diffraction peak intensity. By evaluating the diffraction peaks, it is also observed that the diffraction peaks become sharper and full width at half maxima (FWHM) value is decreased with progression of heat treatment process. The broader crystal peaks are caused due to smaller crystallite sizes and sharp peaks are due to the formation of comparatively larger crystallites. At higher temperature of heat treatment, diffusion of ions in the sample is increased; hence the crystals growth rate is accelerated and larger size crystals result in the glass structure. Judging by the relative intensities of the XRD peaks of these two $\alpha-\mathrm{Zn}_{2} \mathrm{SiO}_{4}$ and $\beta-\mathrm{Zn}_{2} \mathrm{SiO}_{4}$ polymorphs, it can be concluded that $\beta$ $\mathrm{Zn}_{2} \mathrm{SiO}_{4}$ crystallized first at the lower temperatures and then gradually converted to thermodynamically stable $\alpha-\mathrm{Zn}_{2} \mathrm{SiO}_{4}$ by increasing the heat treatment temperature. According to Figure 2, $\alpha-\mathrm{Zn}_{2} \mathrm{SiO}_{4}$ is a single crystalline phase after heat treatment of the glasses at $900^{\circ} \mathrm{C}$. Heat treatment process above $900^{\circ} \mathrm{C}$ leads to better crystallinity of $\alpha-\mathrm{Zn}_{2} \mathrm{SiO}_{4}$ phase, as the sole zinc orthosilicate.

Figure 3 shows the FTIR spectra of the glass-ceramic in the frequency $400-1100 \mathrm{~cm}^{-1}$. The IR spectrum of the glassceramic consists of eight absorption bands. The IR bands and their corresponding vibrational modes for willemite are $460 \mathrm{~cm}^{-1}\left(v_{4}, \mathrm{SiO}_{4}\right), 576 \mathrm{~cm}^{-1}\left(v_{1}, \mathrm{ZnO}_{4}\right), 615 \mathrm{~cm}^{-1}$ $\left(v_{3}, \mathrm{ZnO}_{4}\right), 697 \mathrm{~cm}^{-1}\left(v_{2}, \mathrm{SiO}_{4}\right), 865 \mathrm{~cm}^{-1}\left(v_{1}, \mathrm{SiO}_{4}\right)$, and 905,932 , and $978 \mathrm{~cm}^{-1}\left(v_{3}, \mathrm{SiO}_{4}\right)$ where $v_{1}$ is totally symmetric stretching, $v_{2}$ is bond vibration, $v_{3}$ is asymmetric stretching, and $v_{4}$ is asymmetric deformation [33]. Glassceramic sintered above $700^{\circ} \mathrm{C}$ shows a sharp band at $460 \mathrm{~cm}^{-1}$ that is attributed to the $\mathrm{Si}-\mathrm{O}$ symmetric stretching vibration in $\mathrm{SiO}_{4}$ units. Bands associated with the $\mathrm{Zn}-\mathrm{O}$ symmetric stretching vibration in $\mathrm{ZnO}_{4}$ are located at $577 \mathrm{~cm}^{-1}$ while for asymmetric $\mathrm{Zn}-\mathrm{O}$ stretching they are located at $615 \mathrm{~cm}^{-1}$. The bands positioned at $697 \mathrm{~cm}^{-1}$ and $865 \mathrm{~cm}^{-1}$ are attributed to the $\mathrm{Si}-\mathrm{O}$ bond vibration and $\mathrm{Si}-\mathrm{O}$ symmetric stretching vibration, respectively [34]. On the other hand, the peaks at 905,932 , and $978 \mathrm{~cm}^{-1}$ are assigned to the $\mathrm{Si}-\mathrm{O}$ asymmetric stretching vibration.

FESEM analysis is performed to study the size, shape, and morphology of glass-ceramic. The microstructure observation of the sample revealed well developed willemite crystals in Figures $4(\mathrm{a})-4(\mathrm{e})$. At temperatures $600^{\circ} \mathrm{C}$ and $700^{\circ} \mathrm{C}$, the crystal grains are aggregated and irregular in shape. When the sintering temperature was increased from 800 to $1000^{\circ} \mathrm{C}$, the morphology of the glass-ceramic became granular and initial stage of homogeneous distribution in rhombohedral shaped crystal. From the micrographs, it is clearly observed that the glassy matrices of the treated sample are phase separated with incipient precipitation of defined willemite crystals with increase in heat treatment temperature. The phase separated grains are irregular in shape and distributed uniformly throughout the bulk glass matrix. The grain size is increased by increasing the heat treatment temperature as a result of crystal growth. With increase in heat treatment temperature, these grains are grown with distinct features and composed of few smaller crystals together in the glass matrix. This phase separation followed by crystallization mechanism is a well-known phenomenon for synthesis of glass-ceramics from precursor glass [35].

\section{Conclusion}

In the recent work, the thermal and crystallization of willemite glass-ceramic by controlled crystallization in the $\mathrm{ZnO}$ SLS glass system are demonstrated. The results of XRD, FTIR, and FESEM show the evidence of the formation of willemite crystals in the $\mathrm{ZnO}$-SLS glass matrix. It is found that the willemite phase is obtained from XRD pattern after 


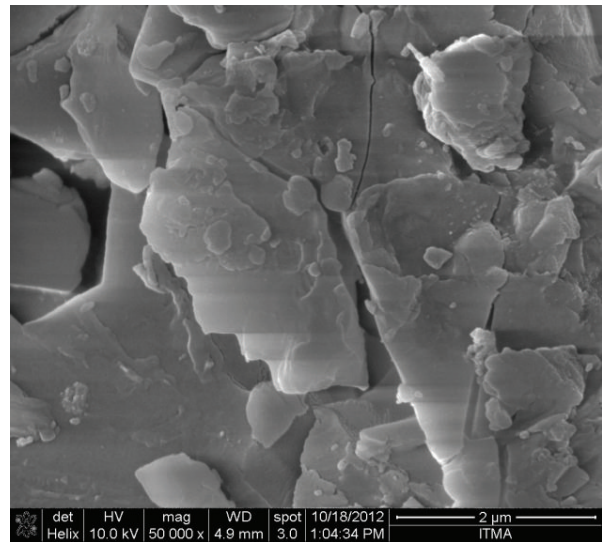

(a)

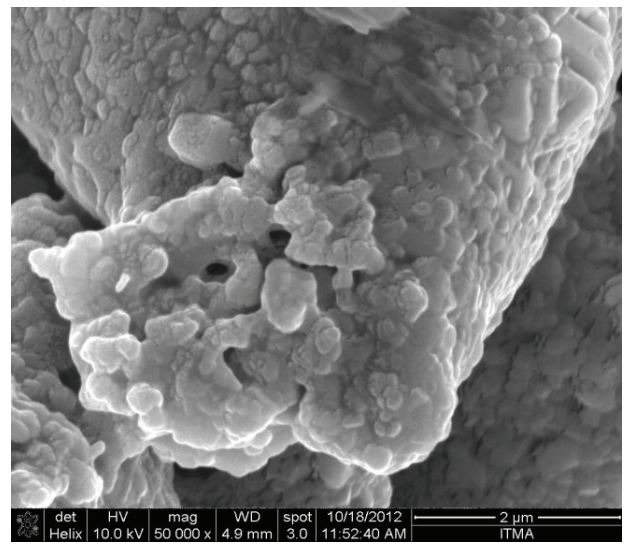

(c)

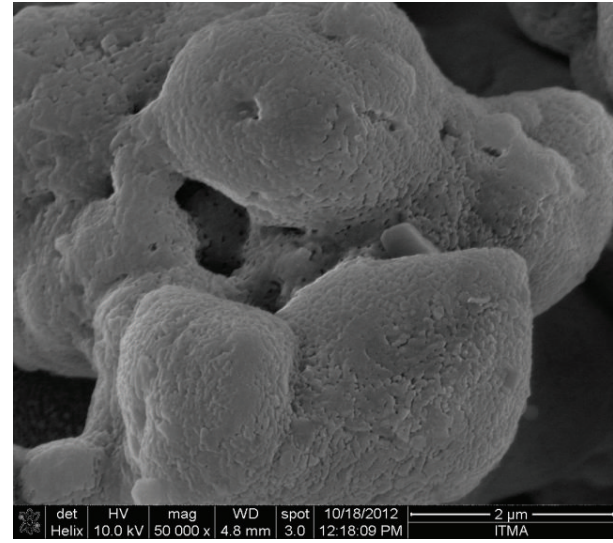

(b)

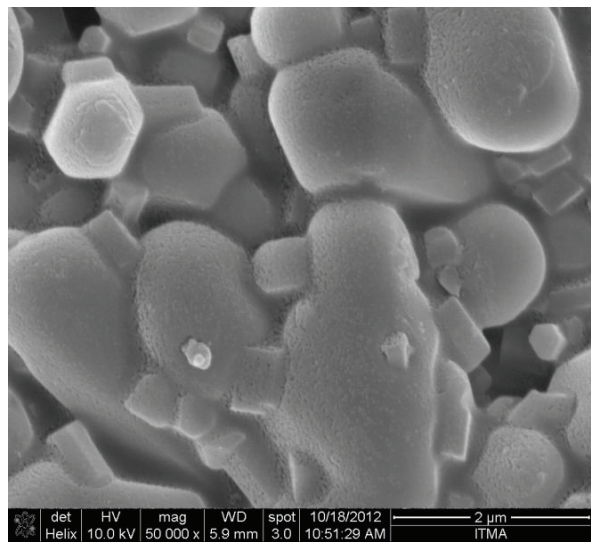

(d)

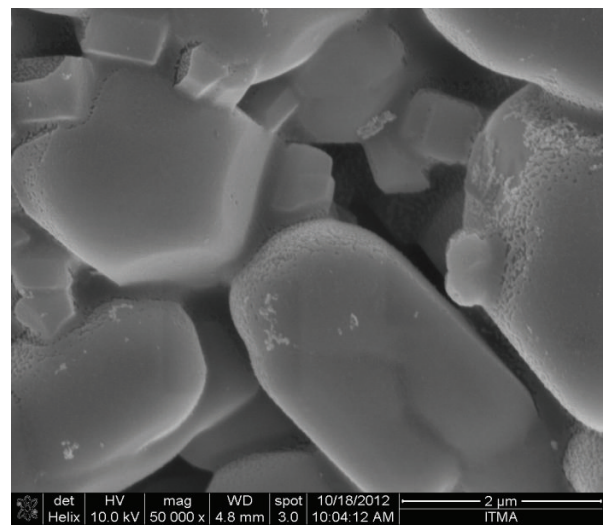

(e)

FIgure 4: Microstructure of the sample treated at (a) $600^{\circ} \mathrm{C}$, (b) $700^{\circ} \mathrm{C}$, (c) $800^{\circ} \mathrm{C}$, (d) $900^{\circ} \mathrm{C}$, and (e) $1000^{\circ} \mathrm{C}$.

the heat treatment process. The FESEM images evidence that, with progression of heat treatment, the glassy matrix initially is phase separated followed by formation of welldefined willemite phases. The appearance of Si-O-Zn vibration bands in FTIR reflectance spectra supports the formation of willemite phase. The FESEM micrographs evidence that the crystallites of willemite glass-ceramics are aggregated and irregular in shape. Therefore, this willemite glass-ceramic appears to be promising for use in the field of optics as a potential phosphors material.

\section{Conflict of Interests}

The authors declare that there is no conflict of interests regarding the publication of this paper.

\section{Acknowledgments}

The researchers gratefully acknowledge the financial support for this study from the Malaysian Ministry of Higher Education (MOHE) and Universiti Putra Malaysia through 
the Fundamental Research Grant Scheme (FRGS) and Inisiatif Putra Berkumpulan (IPB) research grant.

\section{References}

[1] Y. C. Moh and L. A. Manaf, "Overview of household solid waste recycling policy status and challenges in Malaysia," Resources, Conservation and Recycling, vol. 82, pp. 50-61, 2014.

[2] M. H. M. Zaid, K. A. Matori, H. J. Quah et al., "Investigation on structural and optical properties of SLS-ZnO glasses prepared using a conventional melt quenching technique," Journal of Materials Science: Materials in Electronics, vol. 26, no. 6, pp. 3722-3729, 2015.

[3] L. Ding, W. Ning, Q. Wang, D. Shi, and L. Luo, "Preparation and characterization of glass-ceramic foams from blast furnace slag and waste glass," Materials Letters, vol. 141, pp. 327-329, 2015.

[4] A. A. Francis, R. D. Rawlings, R. Sweeney, and A. R. Boccaccini, "Crystallization kinetic of glass particles prepared from a mixture of coal ash and soda-lime cullet glass," Journal of NonCrystalline Solids, vol. 333, no. 2, pp. 187-193, 2004.

[5] K. A. Matori, M. H. M. Zaid, H. A. A. Sidek, M. K. Halimah, Z. A. Wahab, and M. G. M. Sabri, "Influence of $\mathrm{ZnO}$ on the ultrasonic velocity and elastic moduli of soda lime silicate glasses," International Journal of Physical Sciences, vol. 5, no. 14, pp. 2212-2216, 2010.

[6] M. H. M. Zaid, K. A. Matori, L. C. Wah et al., "Elastic moduli prediction and correlation in soda lime silicate glasses containing ZnO," International Journal of Physical Sciences, vol. 6, no. 6, pp. 1404-1410, 2011.

[7] M. H. M. Zaid, K. A. Matori, H. A. A. Sidek, B. Z. Azmi, and M. G. M. Sabri, "Effect of $\mathrm{ZnO}$ on the physical properties and optical band gap of soda lime silicate glass," International Journal of Molecular Sciences, vol. 13, no. 6, pp. 7550-7558, 2012.

[8] I. Ponsot, E. Bernardo, E. Bontempi et al., "Recycling of pre-stabilized municipal waste incinerator fly ash and sodalime glass into sintered glass-ceramics," Journal of Cleaner Production, vol. 89, pp. 224-230, 2015.

[9] J. E. Shelby and M. C. Nichols, "Effect of thermal history on the properties of a willemite glass-ceramic," Journal of the American Ceramic Society, vol. 66, no. 3, pp. 200-204, 1983.

[10] A. M. Hu, M. Li, D. M. Dali, and K. M. Liang, "Crystallization and properties of a spodumene-willemite glass ceramic," Thermochimica Acta, vol. 437, pp. 110-113, 2005.

[11] A. Tarafder, A. R. Molla, C. Dey, and B. Karmakar, "Thermal, structural, and enhanced photoluminescence properties of $\mathrm{Eu}^{3+}$-doped transparent willemite glass-ceramic nanocomposites," Journal of the American Ceramic Society, vol. 96, no. 8, pp. 2424-2431, 2013.

[12] A. Tarafder, A. R. Molla, S. Mukhopadhyay, and B. Karmakar, "Fabrication and enhanced photoluminescence properties of $\mathrm{Sm}^{3+}$-doped $\mathrm{ZnO}-\mathrm{Al}_{2} \mathrm{O}_{3}-\mathrm{B}_{2} \mathrm{O}_{3}-\mathrm{SiO}_{2}$ glass derived willemite glass-ceramic nanocomposites," Optical Materials, vol. 36, no. 9, pp. 1463-1470, 2014.

[13] G. V. Sarrigani, K. A. Matori, W. F. Lim et al., "Structural and optical properties of erbium-doped willemite-based glassceramics," Applied Optics, vol. 54, no. 33, pp. 9925-9929, 2015.

[14] N. F. Samsudin, K. A. Matori, J. Y. C. Liew, Y. W. Fen, M. H. M. Zaid, and Z. N. Alassan, "Investigation on structural and optical properties of willemite doped $\mathrm{Mn}^{2+}$ based glassceramics prepared by conventional solid-state method," Journal of Spectroscopy, vol. 2015, Article ID 730753, 7 pages, 2015.
[15] E. Ozel, H. Yurdakul, S. Turan, M. Ardit, G. Cruciani, and M. Dondi, "Co-doped willemite ceramic pigments: technological behaviour, crystal structure and optical properties," Journal of the European Ceramic Society, vol. 30, no. 16, pp. 3319-3329, 2010.

[16] C. Feldmann, T. Jüstel, C. R. Ronda, and P. J. Schmidt, "Inorganic luminescent materials: 100 years of research and application," Advanced Functional Materials, vol. 13, no. 7, pp. 511-516, 2003.

[17] T. C. Brunold, H. U. Gudel, and E. Cavalli, "Absorption and luminescence spectroscopy of $\mathrm{Zn}_{2} \mathrm{SiO}_{4}$ willemite crystals doped with $\mathrm{Co}^{2+}$," Chemical Physics Letters, vol. 252, no. 1-2, pp. 112120, 1996.

[18] P. Gerner, C. Fuhrer, C. Reinhard, and H. U. Güdel, "Nearinfrared to visible photon upconversion in $\mathrm{Mn}^{2+}$ and $\mathrm{Yb}^{3+}$ containing materials," Journal of Alloys and Compounds, vol. 380, no. 1-2, pp. 39-44, 2004.

[19] K. Watanabe, "Growth of willemite, $\mathrm{Zn}_{2} \mathrm{SiO}_{4}$, single crystals from a $\mathrm{Li}_{2} \mathrm{MoO}_{4}$ solvent," Journal of Crystal Growth, vol. 114, no. 3, pp. 373-379, 1991.

[20] M. Takesue, A. Suino, K. Shimoyama, Y. Hakuta, H. Hayashi, and R. L. Smith Jr., "Formation of $\alpha$ - and $\beta$-phase Mndoped zinc silicate in supercritical water and its luminescence properties at $\mathrm{Si} /(\mathrm{Zn}+\mathrm{Mn})$ ratios from 0.25 to 1.25 ," Journal of Crystal Growth, vol. 310, no. 18, pp. 4185-4189, 2008.

[21] N. F. Syamimi, K. A. Matori, W. F. Lim, S. Abdul Aziz, and M. H. M. Zaid, "Effect of sintering temperature on structural and morphological properties of europium (III) oxide doped willemite," Journal of Spectroscopy, vol. 2014, Article ID 328931, 8 pages, 2014.

[22] G. V. Sarrigani, H. J. Quah, W. F. Lim et al., "Characterization of waste material derived willemite-based glass-ceramics doped with erbium," Advances in Materials Science and Engineering, vol. 2015, Article ID 953659, 7 pages, 2015.

[23] Y. Guo, H. Ohsato, and K. Kakimoto, "Characterization and dielectric behavior of willemite and $\mathrm{TiO}_{2}$-doped willemite ceramics at millimeter-wave frequency," Journal of the European Ceramic Society, vol. 26, pp. 1827-1830, 2006.

[24] T. Minami, T. Miyata, S. Takata, and I. Fukuda, "Highluminance green $\mathrm{Zn}_{2} \mathrm{SiO}_{4}: \mathrm{Mn}$ thin-film electroluminescent devices using an insulating $\mathrm{BaTiO}_{3}$ ceramic sheet," Japanese Journal of Applied Physics, vol. 30, no. 1, pp. L117-L119, 1991.

[25] Y. C. Kang and S. B. Park, " $\mathrm{Zn}_{2} \mathrm{SiO}_{4}: \mathrm{Mn}$ phosphor particles prepared by spray pyrolysis using a filter expansion aerosol generator," Materials Research Bulletin, vol. 35, no. 7, pp. 11431151, 2000.

[26] T. S. Copeland, B. I. Lee, J. Qi, and A. K. Elrod, "Synthesis and luminescent properties of $\mathrm{Mn}^{2+}$-doped zinc silicate phosphors by sol-gel methods," Journal of Luminescence, vol. 97, no. 3-4, pp. 168-173, 2002.

[27] A. Roy, S. Polarz, S. Rabe et al., "First preparation of nanocrystalline zinc silicate by chemical vapor synthesis using an organometallic single-source precursor," Chemistry, vol. 10, no. 6, pp. 1565-1575, 2004.

[28] J. H. Zeng, H. L. Fu, T. J. Lou, Y. Yu, Y. H. Sun, and D. Y. $\mathrm{Li}$, "Precursor, base concentration and solvent behavior on the formation of zinc silicate," Materials Research Bulletin, vol. 44, no. 5, pp. 1106-1110, 2009.

[29] A. R. Boccaccini, W. Stumpfe, D. M. R. Taplin, and C. B. Ponton, "Densification and crystallization of glass powder compacts during constant heating rate sintering," Materials Science and Engineering: A, vol. 219, no. 1-2, pp. 26-31, 1996. 
[30] H. A. Abo-Mosallam, H. Darwish, and S. M. Salman, "Crystallization characteristic and properties of some zinc containing soda lime silicate glasses," Journal of Materials Science: Materials in Electronics, vol. 21, no. 9, pp. 889-896, 2010.

[31] J. Williamson and F. P. Glasser, "Crystallisation of zinc silicate liquids and glasses," Physics and Chemistry of Glasses, vol. 5, pp. 52-59, 1964.

[32] H. Yang, R. M. Hazen, R. T. Downs, and L. W. Finger, "Structural change associated with the incommensurate-normal phase transition in akermanite, $\mathrm{Ca}_{2} \mathrm{MgSi}_{2} \mathrm{O}_{7}$, at high pressure," Physics and Chemistry of Minerals, vol. 24, no. 7, pp. 510-519, 1997.

[33] C. C. Lin and P. Shen, "Sol-gel synthesis of zinc orthosilicate," Journal of Non-Crystalline Solids, vol. 171, no. 3, pp. 281-289, 1994.

[34] M. Mai and C. Feldmann, "Two-color emission of $\mathrm{Zn}_{2} \mathrm{SiO}_{4}: \mathrm{Mn}$ from ionic liquid mediated synthesis," Solid State Sciences, vol. 11, no. 2, pp. 528-532, 2009.

[35] F. J. Torres, E. R. de Sola, and J. Alarcon, "Mechanism of crystallization of fast fired mullite-based glass-ceramic glazes for floor-tiles," Journal of Non-Crystalline Solids, vol. 352, no. 2122, pp. 2159-2165, 2006. 

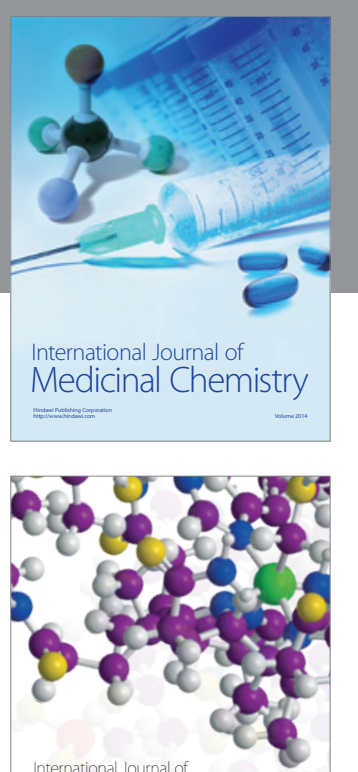

Carbohydrate Chemistry

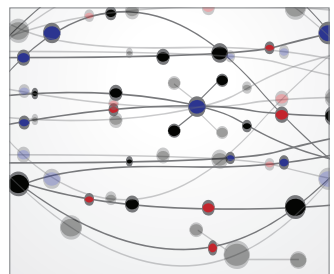

The Scientific World Journal
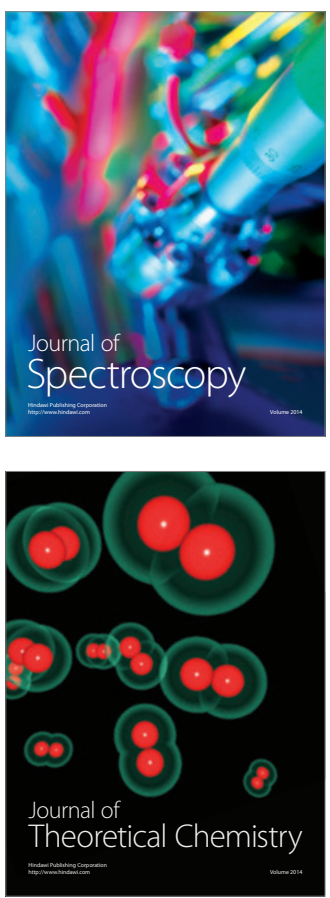
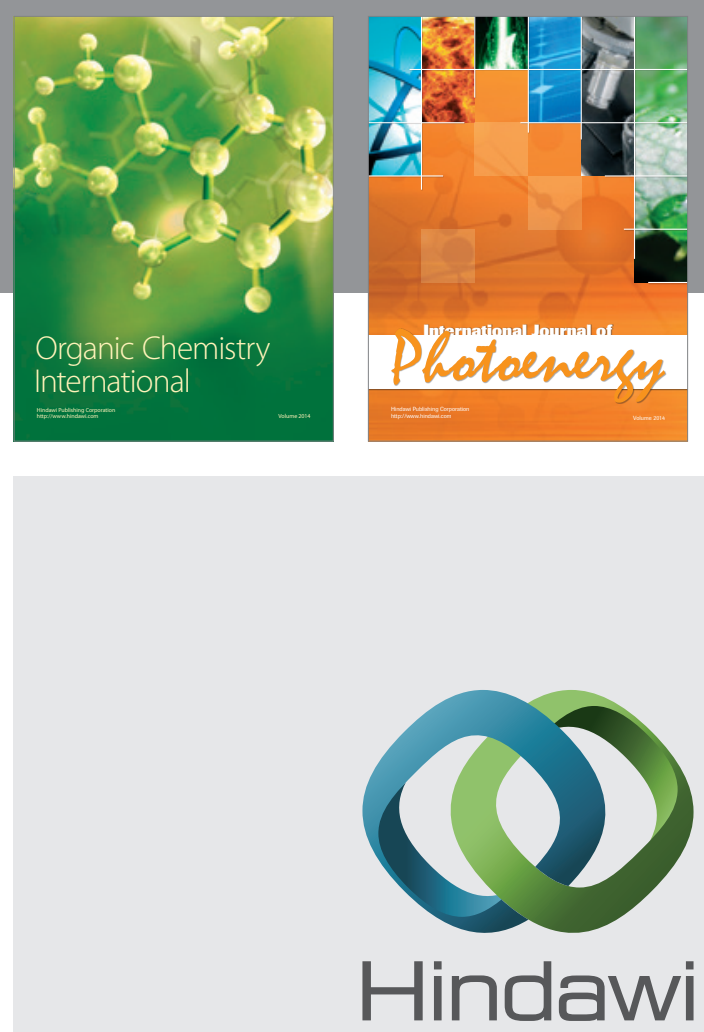

Submit your manuscripts at

http://www.hindawi.com

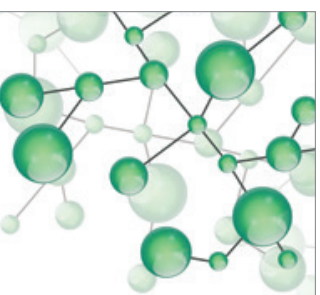

International Journal of

Inorganic Chemistry

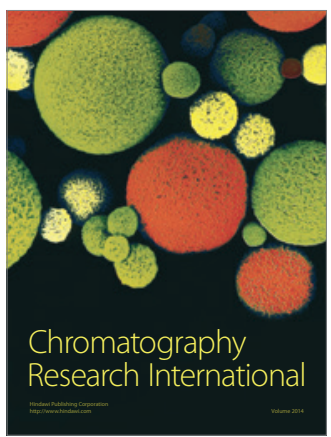

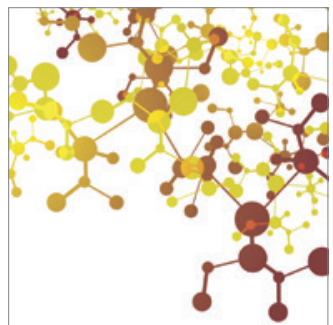

Applied Chemistry
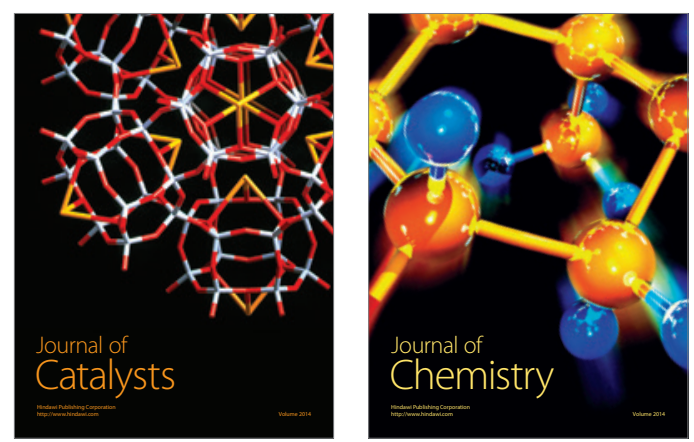
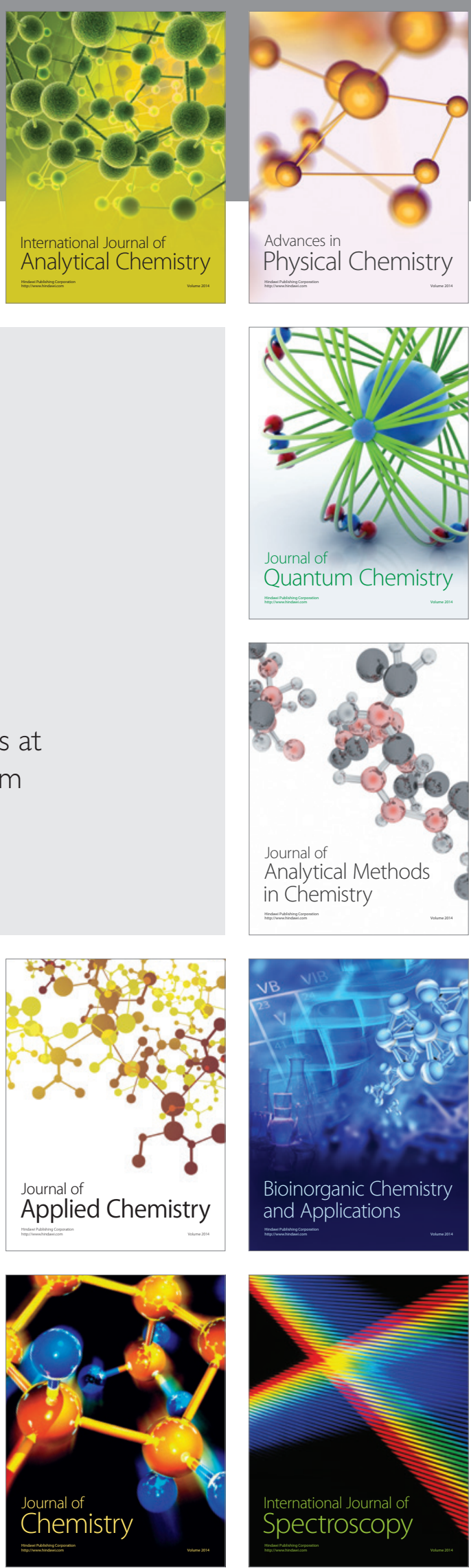